\title{
Thanatophoric dysplasia. A case report and review
}

\author{
Alejandro Giraldo-Cuartas, M.D.*
}

Recibido: julio 23/08 - Aceptado: octubre 28/08

\section{RESUMEN}

Objetivo: presentar los hallazgos ecográficos de la displasia tanatofórica (DT) y su diagnóstico diferencial, desde el punto de vista del ultrasonido con la acondroplasia.

Se presenta un caso clínico de una paciente gestante a quien se remitió con diagnóstico de feto con acondroplasia, y posterior a una ecografía de detalle fetal 2D-3D, se hizo el diagnóstico antenatal de displasia tanatofórica (DT), el cual se confirmó postmortem.

Conclusión: se resalta la necesidad de afinar los criterios diagnósticos de la restricción del crecimiento, partiendo de reportar los hallazgos ecográficos en función del percentil de crecimiento fetal y no de la reasignación de una nueva edad gestacional con cada nueva ecografía, además se hacen algunas recomendaciones respecto al informe ecográfico.

Palabras clave: displasia tanatofórica, enanismo tanatofórico.

\section{SUMMARY}

Objective: the article presents a clinical case of a 29-week pregnant woman, with a previous Achondroplasia diagnosis, but after a detail ultrasound scan (2D-3D) a Thanatophoric Dysplasia (DT) was found and confirmed postmortem.

* Médico Ginecobstetra, Universidad de Caldas. Entrenamiento en ultrasonido y diagnóstico prenatal Hospital González Coro, La HabanaCuba. Consultorio médico de la mujer- Manizales. Imágenes diagnósticas Teusa, Bogotá, Colombia. Correo electrónico: Alejo.gc@hotmail.com
Conclusion: the article emphasizes in the scan interpretation of the characteristic findings of the DT and the differential diagnostic with Achondroplasia, as well as the need to focus the restriction growth diagnosis criteria on function of the fetal growth curve, not reassigning a new gestational age with each new scan. Some recommendations respect to ultrasonography report are given.

Key words: thanatophoric dysplasia, thanatophoric dwarfism.

\section{INTRODUCCIÓN}

Las displasias esqueléticas son patologías raras que se han clasificado en numerosos trastornos esqueléticos. ${ }^{1}$ Sólo algunas displasias se pueden detectar con precisión mediante ecografía prenatal. Unas cuantas comparten una característica básica, como es el acortamiento de los huesos largos, lo cual presenta un desafío para el ultrasonido: diferenciar si se trata de una restricción del crecimiento intrauterino (para lo cual es indispensable conocer la edad gestacional por amenorrea o ecografía del primer trimestre) o de un tipo de enanismo; pero sobre todo plantea un gran interrogante respecto a su letalidad, lo que hace que la exploración esquelética requiera un estudio secuencial de los huesos largos, el tórax, la columna vertebral, el cráneo, la pelvis, las manos y los pies fetales..$^{2-3}$ Aunque este tipo de anomalías son relativamente raras y tienen una prevalencia al nacer ${ }^{3}$ de 2 a 3 por cada 10.000; por su impacto, tanto para el embarazo que curse con un feto dismórfico, como para el futuro reproductivo 
de la pareja, el ecografista y todo el grupo médico al cuidado de la paciente deben tener siempre presente este tipo de patologías. ${ }^{2}$

Si bien la ecografía permite medir los huesos largos desde la décima semana de gestación, y las deformidades de las extremidades se pueden detectar desde el inicio del segundo trimestre, un diagnóstico tardío de una condición letal aumenta innecesariamente los riesgos para la salud física y mental de la paciente.

\section{CASO CLÍNICO}

Se trata de una paciente de 19 años, procedente de un área rural del departamento de Caldas, situado en la región central de Colombia, que llegó remitida por contracciones uterinas y hallazgos en ecografía de tamizaje de: embarazo de 29 semanas, acondroplasia y polihidramnios. Antecedentes ginecobstétricos G: 2, P: 1, A: 0, V: 1; fecha de la última menstruación: 20 de abril de 2007. En el examen físico se encontró: altura uterina de $38 \mathrm{~cm}$, frecuencia cardíaca fetal de 150 por minuto y, al tacto vaginal, cuello largo con $2 \mathrm{~cm}$ de dilatación.

Se realizó una ecografía de detalle fetal, encontrando un feto femenino, con evidente polihidramnios y restricción del crecimiento, además de otros marcadores como frente prominente, puente nasal bajo, discreto hipertelorismo y orejas de implantación baja (figuras 1,2).

Figura 1.

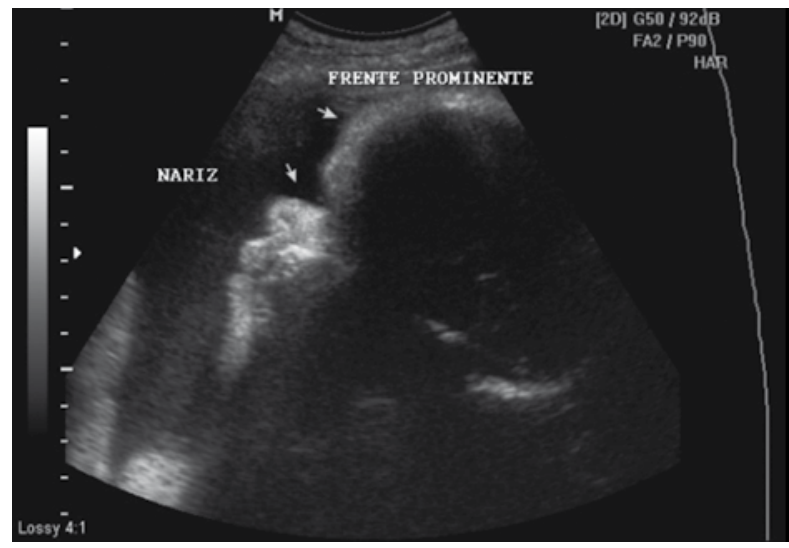

Figura 2.

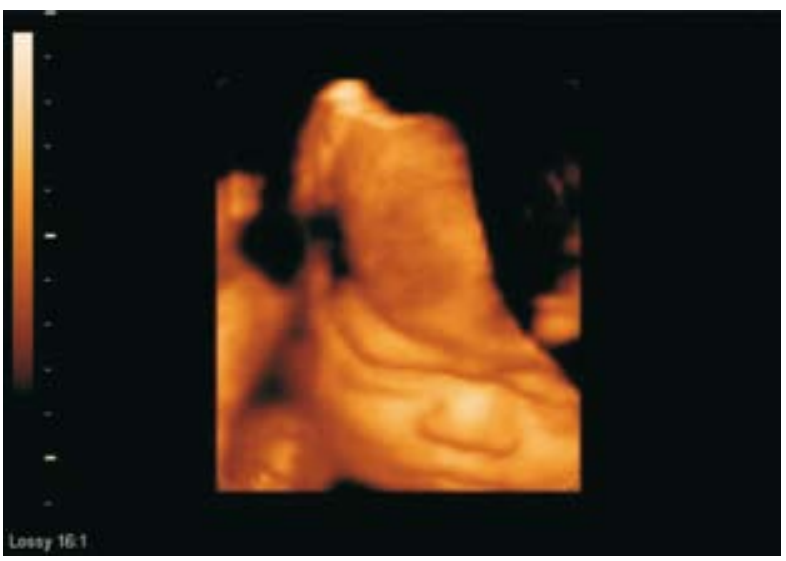

Tórax estrecho en forma de campana, con perímetro torácico estrecho, alteración de la proporción tóraco-abdominal, con abdomen abombado (figuras 3,4 ) y con notable hipoplasia pulmonar (figura 5).

Figura 3.

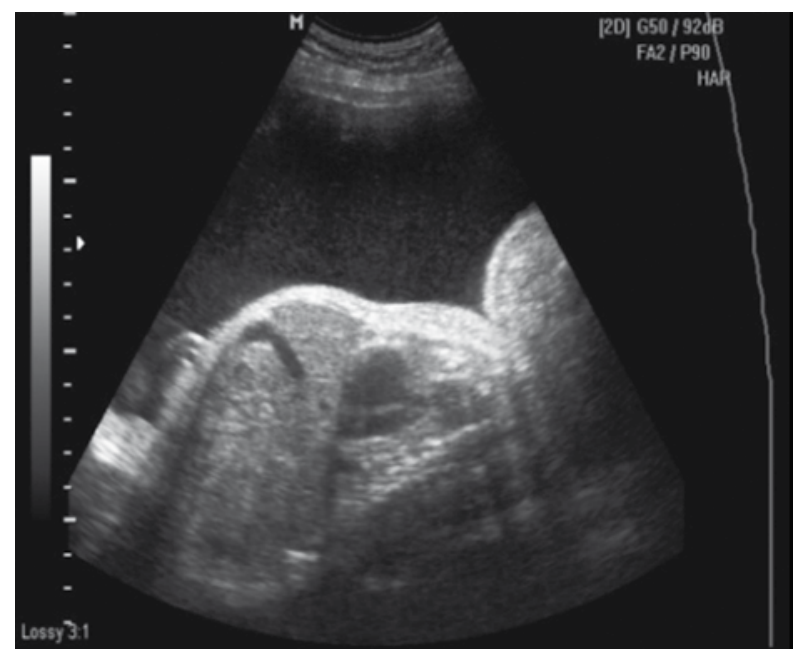

Micromelia de las cuatro extremidades (figuras 6,7), dedos cortos (figuras 8,9), pliegues de piel y tejidos blandos que dan la apariencia de “muñeco Michelin" (figuras 9-10), característico fémur corto (figuras 11,12) y tórax en campana (figura 13). 
Figura 4.

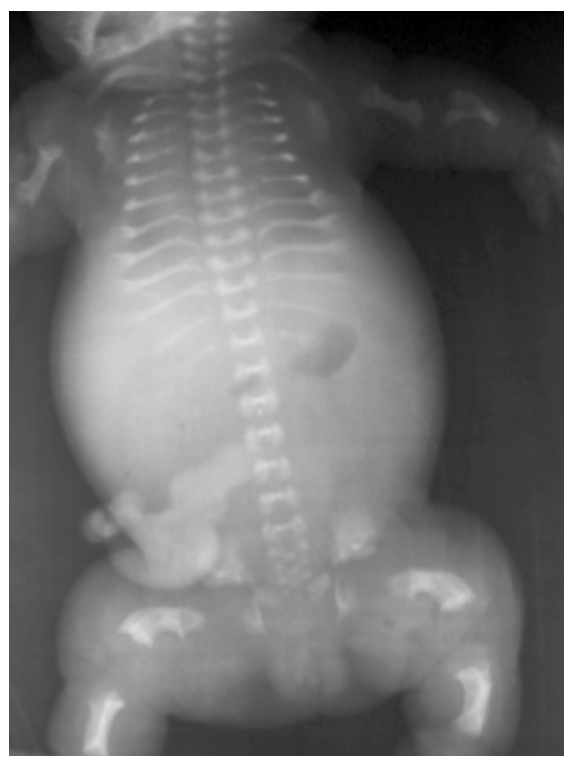

Figura 6.

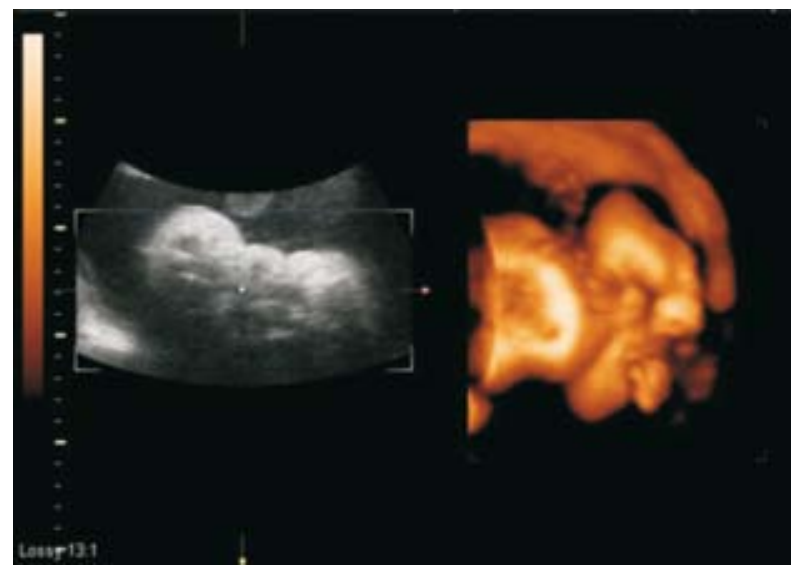

Figura 8.

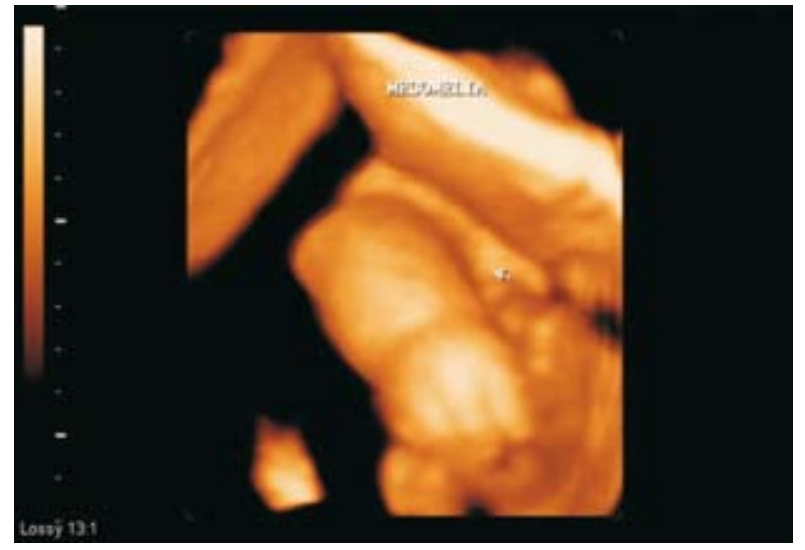

Figura 5.

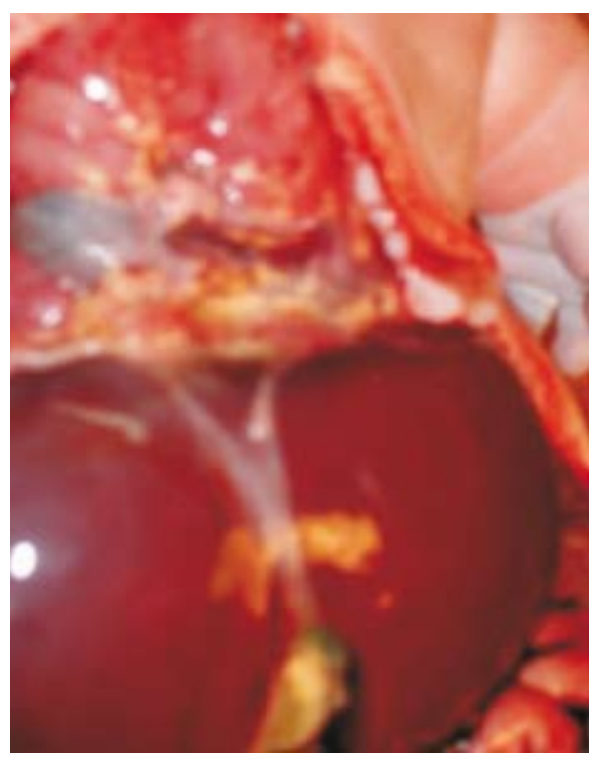

Figura 7.

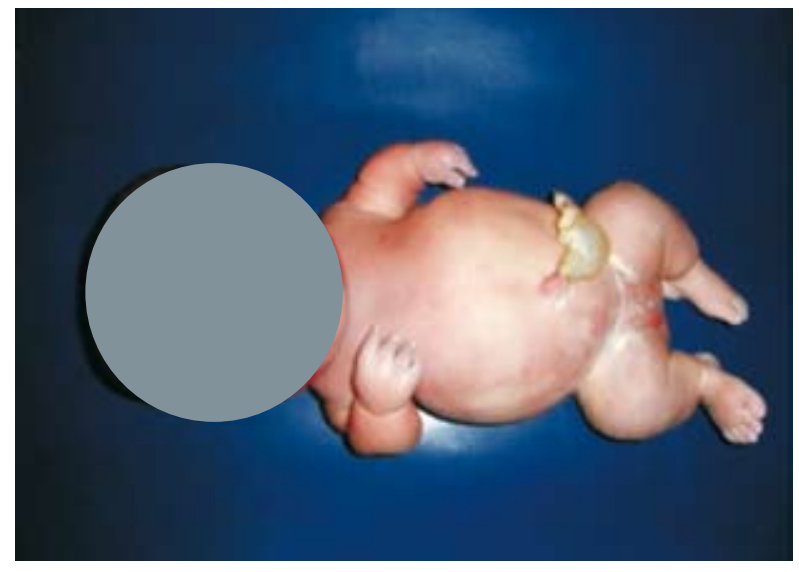

Figura 9.

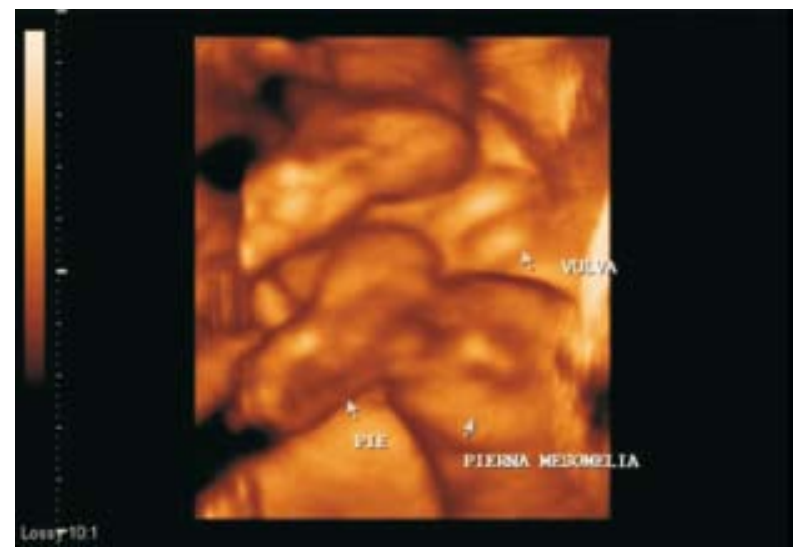


Figura 10.

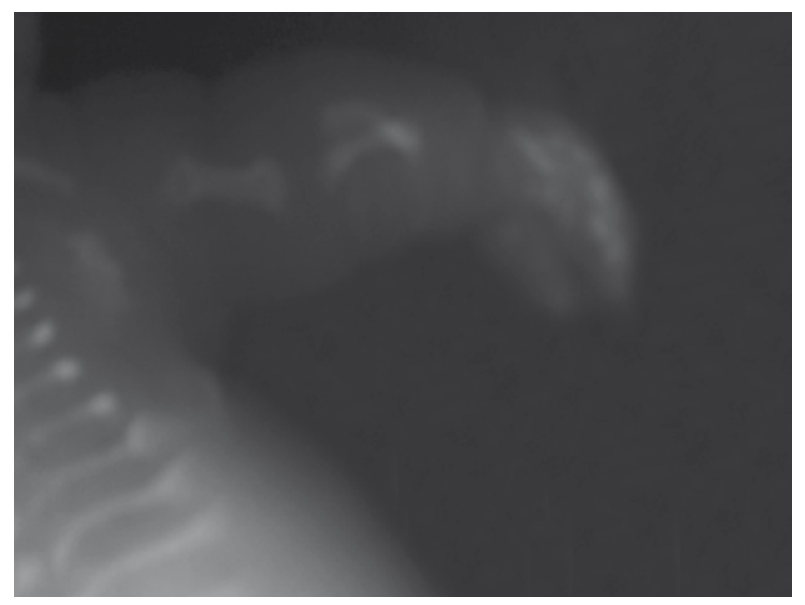

Figura 12.

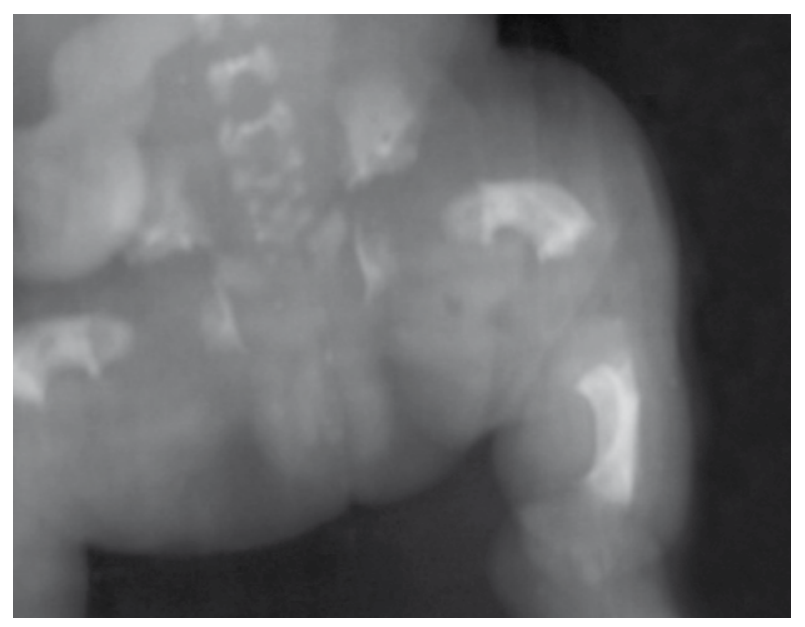

No se encontraron otras alteraciones morfológicas en el estudio ultrasonográfico, se hizo diagnóstico de displasia tanatofórica tipo I y se iniciaron esteroides por consideraciones éticas. La paciente presentó nuevamente contracciones uterinas espontáneas, evolucionó y tuvo parto vaginal de un feto vivo de sexo femenino, con peso fetal $1.830 \mathrm{~g}$, talla $32 \mathrm{~cm}$, perímetro cefálico $33 \mathrm{~cm}$, perímetro torácico $22 \mathrm{~cm}$, sin mayor esfuerzo respiratorio y Apgar 4 al minuto, falleciendo a los 15 minutos. Se realizó el respectivo estudio postmortem que confirmó los hallazgos ecográficos.
Figura 11.

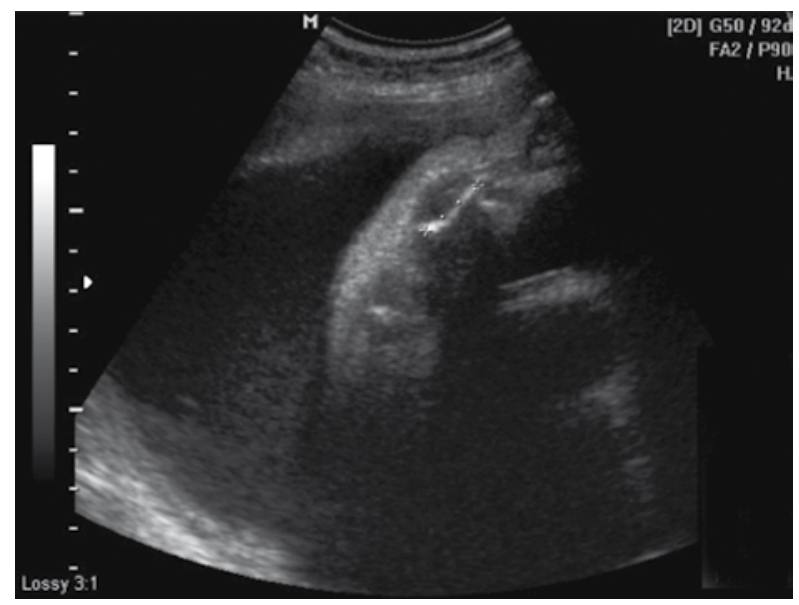

Figura 13.

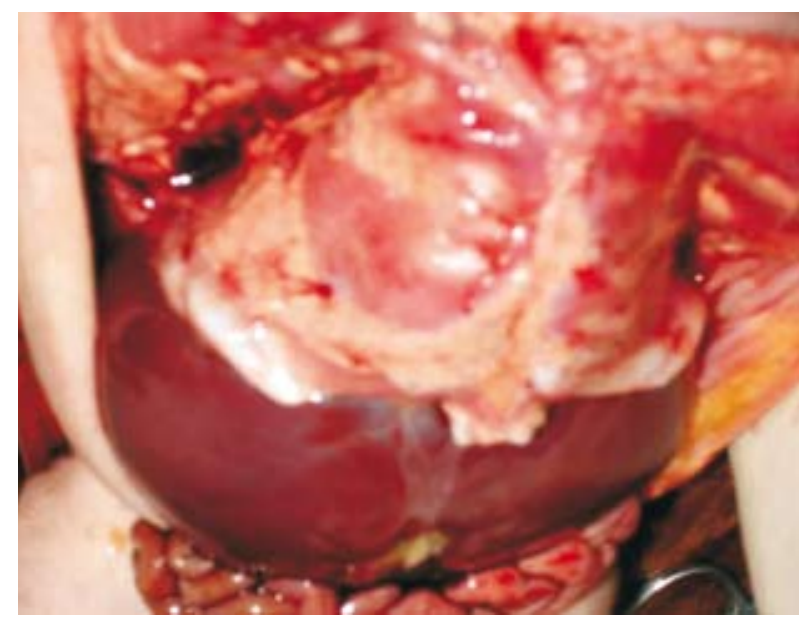

\section{DISCUSIÓN}

Las displasias esqueléticas tienen una prevalencia al nacimiento estimada en 2,4 por cada 10.000. Dentro de ellas, la displasia tanatofórica (DT) o enanismo tanatofórico, ${ }^{1-4}$ es la más común de las displasias esqueléticas letales, con una frecuencia muy variable dependiendo de la fuente consultada ${ }^{3-6}$ y el país referenciado, y puede ir desde menos de 1 por 10.000 a 1 por 40.0000 nacidos vivos. Las frecuencias relativas de las diferentes displasias esqueléticas reseñada por Jeanty ${ }^{2}$ se muestran en la figura 14 (reproducido con permiso de TheFetus.net). 
Figura 14

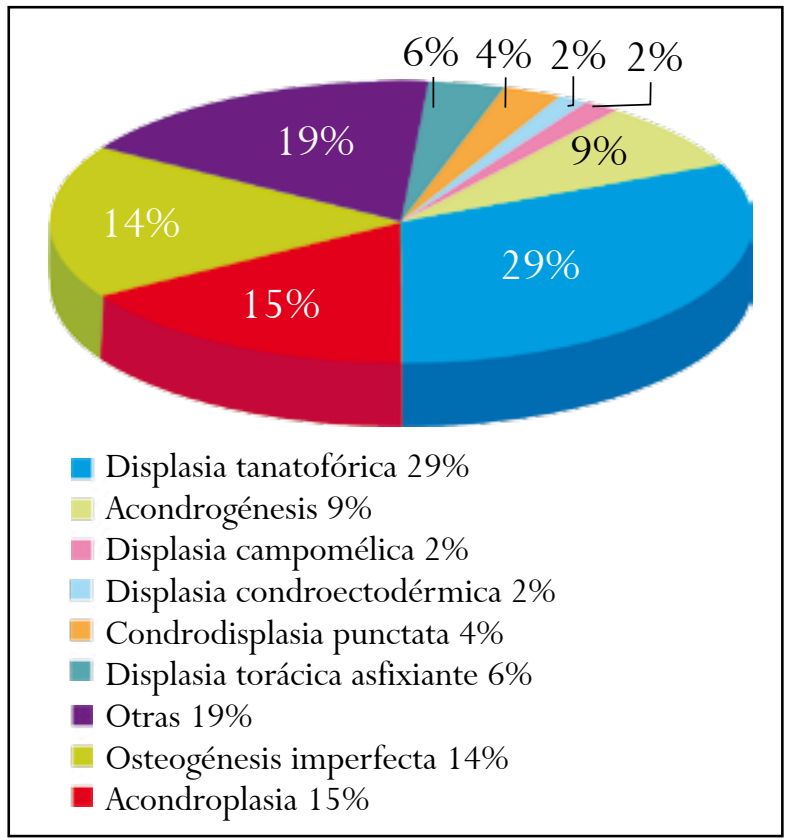

No ha sido reportado predominio por sexo; la mayoría de los autores proponen un patrón de herencia autosómica dominante, producida por una mutación en el receptor 3 del factor de crecimiento de fibroblastos FGFR3 en el cromosoma 4p16,3; porque una copia mutada del gen FGFR3 en cada célula es suficiente para causar esta condición. ${ }^{7}$ Virtualmente todos los casos de DT son causados por nuevas mutaciones en el gen FGFR3 y ocurren en personas sin antecedentes en su familia, de manera que individuos sanos han tenido hijos con DT y por su letalidad no han pasado a la siguiente generación. ${ }^{7}$ Esta mutación, que resulta de novo, aparece esporádicamente produciendo una incompleta osificación de los osteocitos. Se describen dos subtipos: para la DT tipo I existe sustitución de aminoácidos arg248cys en el 50\% de los pacientes, y en DT tipo II lys650glu. ${ }^{7}$ Dado que la mutación adicionalmente dispara la actividad de la tirosina cinasa del receptor, y como normalmente FGFR3 es un regulador negativo del crecimiento, la mutación permite al receptor activado enviar señales negativas dentro de los condrocitos, llevando a una desorganización generalizada de la osificación endocondral en el plato epifisiario del hueso fetal. ${ }^{6-8}$
La DT está caracterizada por extrema rizomelia, pliegues de piel redundantes en las extremidades, longitud del tronco normal, tórax estrecho, costillas pequeñas y cabeza grande con frente prominente, nariz en silla de montar y abdomen protuberante. Se trata de un tipo de enanismo de miembros cortos, con acortamiento y arqueo de los huesos largos. Los lactantes afectados nacen muertos o mueren al cabo de algunas horas del parto, debido a la hipoplasia pulmonar. $^{3}$ Se han identificado dos subtipos desde el punto de vista clínico: tipo I, con el típico fémur curvo en "auricular de teléfono", sin cráneo en hoja de trébol y frente prominente, hipertelorismo, nariz en silla de montar; y a nivel de columna platispondilia, con micromelia de las cuatro extremidades, manos y pies normales, pero dedos cortos.

El tipo II en el 14\% de los $\operatorname{casos}^{9}$ tiene huesos cortos rectos y una forma de craneosinostosis llamada cráneo en hoja de trébol. ${ }^{9-11}$ El trastorno se hereda con carácter autosómico dominante y todos los casos se deben a mutaciones genéticas de novo. ${ }^{712-14}$

La DT está asociada con otras alteraciones como hidrocefalia (en los casos de cráneo en trébol), riñón en herradura, defecto septal atrial, defecto de la válvula tricúspide, ano imperforado y sinostosis radiocubital. ${ }^{4-9}$

Los hallazgos ecográficos dependen del tipo. La asociación de cráneo en trébol y micromelia es específica de la displasia tanatofórica. El cráneo en trébol puede resultar de: 1) cierre prematuro de las suturas coronal y lambdoidea, 2) un defecto en el desarrollo de la base del cráneo con sinostosis secundaria, o 3) un desorden primario del desarrollo del cerebro con deformidad secundaria del cráneo; pueden estar presentes: frente prominente, nariz en silla de montar e hipertelorismo, así como ventriculomegalia, aplanamiento vertebral (platispondilia) y polihidramnios. La displasia tanatoforica es uniformemente letal. ${ }^{6}$

$\mathrm{Al}$ igual que otras displasias óseas, la DT puede ser detectada durante la gestación, mediante la ecografía prenatal de tamizaje, y ante la sospecha de una displasia de este tipo, es necesario hacer estudios dirigidos para confirmar la sospecha (ecografía de 
detalle y tridimensional), ${ }^{10}$ también es posible hacer un diagnóstico molecular en etapas tempranas del embarazo. ${ }^{5}$ Respecto a la consejería genética, debido a que la presentación de la DT se debe a una mutación autosómica dominante de novo, el riesgo de recurrencia no es mayor que el de la población general. ${ }^{8}$ El diagnóstico prenatal es confiable por ultrasonido, como en este caso, y también por estudio molecular de células fetales obtenidas por amniocentesis o biopsia corial.

Otros diagnósticos diferenciales son la acondroplasia homocigota, displasia camptomélica, acondrogénesis, displasia torácica asfixiante (síndrome de Jeune), hipofosfatasia, osteogénesis imperfecta, fibrocondrogénesis, displasia condroectodérmica (síndrome de Ellis van Creveld) y los síndromes de Apert, Crouzon, Pfeiffer y Carpenter, además del síndrome de costilla corta polidactilia., ${ }^{2,15-17}$

Dado que la acondroplasia hace parte del grupo de las displasias esqueléticas, sus características y su pronóstico hacen que sea imprescindible su clara diferenciación con la displasia tanatofórica en el diagnóstico prenatal, como en el caso aquí descrito. La acondroplasia, término impreciso pues denota ausencia de cartílago en lugar de cartílago anormal, ${ }^{18-19}$ es la displasia esquelética no letal más común, producida por una mutación diferente en el mismo gen que codifica el receptor 3 del factor de crecimiento de fibroblastos (FGFR3). Está caracterizada por un enanismo rizomélico, extremidades curvas, espina lordótica, cabeza grande, perfil facial anormal, puente nasal aplanado, mandíbula ancha, longitud normal del tronco y lordosis. La acondroplasia heterocigota es compatible con una vida normal, mientras que la homocigota es letal. ${ }^{4,18}$ La herencia es autosómica dominante, pero en los casos en que los padres están sanos la acondroplasia se debe a una mutación nueva. Los primeros signos de acortamiento de las extremidades pueden aparecer hacia las 24 semanas de embarazo, o pueden aparecer más tardíamente, incluso en el tercer trimestre. ${ }^{3}$

Recordemos a continuación cuáles son las causas de acortamiento de los huesos largos. ${ }^{20}$ Tabla 1

\begin{tabular}{|l|c|}
\hline \multicolumn{2}{|c|}{ Tabla 1. } \\
\hline \multicolumn{1}{|c|}{ Frecuentes } & \multicolumn{1}{|c|}{ Infrecuentes } \\
\hline Error en la medición. & $\begin{array}{c}\text { Desórdenes } \\
\text { cromosómicos. }\end{array}$ \\
\hline $\begin{array}{l}\text { Asignación incorrecta } \\
\text { de la edad gestacional. }\end{array}$ & Displasias esqueléticas. \\
\hline Feto pequeño. & Hipoplasia femoral. \\
\hline $\begin{array}{l}\text { Restricción simétrica del } \\
\text { crecimiento. }\end{array}$ & \\
\hline
\end{tabular}

\section{RECOMENDACIONES}

$\mathrm{Al}$ realizar una ecografía obstétrica, existe la posibilidad de enfrentarnos a una displasia esquelética y por esta razón la evaluación detallada de la anatomía fetal es una parte integrante del examen. ${ }^{3}$ Una recomendación importante es confirmar la edad gestacional antes de realizar el barrido ecográfico, dado que si la amenorrea no es confiable, se debe establecer de acuerdo a la ecografía del primer trimestre y de allí en adelante no cambiarla. Nunca se debe establecer la edad gestacional con base en el tamaño del feto (es una falsa premisa que mientras más grande más edad gestacional), pues se puede incurrir en el error de no diagnosticar una macrosomía fetal, una restricción del crecimiento intrauterino, o una displasia esquelética.

Si bien la biometría de los huesos largos ha sido usada extensamente en la predicción de la edad gestacional, los nomogramas disponibles para este propósito usan los huesos largos como la variable independiente, y la edad fetal estimada como la variable dependiente. Sin embargo, el tipo de nomograma requerido para valorar la normalidad de las dimensiones óseas (y por consiguiente el crecimiento) debe usar, al contrario, la edad gestacional como la variable independiente y los huesos largos como la variable dependiente; ${ }^{2}$ es decir, lo que cambia es la longitud de los huesos no la edad. Debemos, por tanto, cuidarnos de estar cambiando la edad gestacional a expensas de evaluar el crecimiento fetal.

Por otra parte, en el momento actual del ejercicio profesional, en el que las relaciones entre 
médico y enfermo han sufrido un cambio de $180^{\circ}$, es recomendable para quien realice ecografías, que siempre deje constancia de que algunas alteraciones pueden aparecer tardíamente en el embarazo o sólo pueden ser diagnosticadas con el transcurso de la gestación, y que incluso la evaluación ecográfica exhaustiva durante el segundo trimestre no permite detectar todas las malformaciones estructurales. Es posible que anomalías como la hidrocefalia, la atresia duodenal, la microcefalia, la poliquistosis renal y la acondroplasia, ${ }^{18}$ no se manifiesten hasta el tercer trimestre, cuando el grado de distorsión anatómica es suficiente para poder detectarlo mediante ecografía. ${ }^{3}$ Del mismo modo, una ecografía de la semana 22, así sea "normal" (término riesgoso que debería cambiarse por "sin alteraciones estructurales aparentes al momento del examen"), no descarta su presencia posterior, pues recordemos que el acortamiento de los huesos largos sólo ocurren en esta última entidad, después de las 24 semanas.

\section{AGRADECIMIENTOS}

Dr. Guillermo López Guarnido, Médico Patólogo Citosalud Manizales.

\section{REFERENCIAS}

1. International Nosology and Classification of Constitutional Disorders of Bone. Visitado en 2008 Oct 22. Disponible en: http://www.csmc. edu/pdf/internationalNosologyandcla.pdf

2. Jeanty P, Valero G. The Assessment of the fetus with a skeletal dysplasia. Visitado en 2008 Oct 22. Disponible en: http://www.thefetus.net/files/skeletal_eng.PDF

3. Carrera JM, Kurjak A. Ecografía en diagnóstico prenatal. Barcelona: Elsevier Masson; 2008.

4. Clavelli W. Evaluación ultrasonográfica de las alteraciones esqueléticas. En: Cafici D, Mejides A, Sepúlveda W. Ultrasonografía en obstetricia y diagnóstico prenatal. Buenos Aires: Ediciones Journal; 2003. p. 379-410.

5. Padilla RAL, Duran PMA, Davies BR. Displasia tanatofórica: Revisión de criterios diagnósticos en 5 casos de autopsia. Rev Mex Pediat 2005;72:126-32.
6. Carter M Suzanne, Gross J Susan. Thanatophoric Dysplasia. Am J Med Genet 1997. Visitado en 2008 Oct 22. Disponible en: www.emedicine.com/ped/ topic2233.htm

7. Genetics Home Reference, published July 112008. Visitado en 2008 Oct 22. Disponible en: http//ghr. nlm.nih.gov/gene $=$ fgfr3

8. Liboi E, Lievens PMJ. Thanatophoric Dysplasia. Orphanet encyclopedia. September 2004. Visitado en 2008 Oct 22. Disponible en: http://www.orpha. net/data/patho/GB/uk-thanatophoric-dysplasia.pdf.

9. Norris ChD, Tiller G, Jeanty P, Malini S. Thanatophoric dysplasia in monozygotic twins. 1994-12-28-07. Visitado en 2008 Oct 22. Disponible en: http://www. TheFetus.net/page.php?id $=383$

10. Schild RL, Hunt GH, Moore J, Davies H, Horwell DH. Antenatal sonographic diagnosis of thanatophoric dysplasia: a report of three cases and a review of the literature with special emphasis on the differential diagnosis. Ultrasound Obstet Gynecol 1996,8:62-7.

11. Sherer DM, Ghezzi F, Cohen J, Romero R. Fetal skeletal anomalies. En: Fleischer A, Manning F, Jeanty P, Romero R. Sonography in obstetrics and gynecology. 5th.ed. Stamford, Connecticut: Appleton \& Lange; 1996. p. 447-91.

12. Jones KL. Smith. Patrones Reconocibles de Malformaciones Humanas. Barcelona: Elsevier; 2006. p. 382-86.

13. Mancilla EE, Poggy H, Repetto G, García C, Foradori A, Cattani A. Mutaciones del gen del receptor 3 del Factor de Crecimiento de Fibroblasto (FGFR3) en pacientes chilenos con talla baja idiopática, hipocondroplasia y acondroplasia. Rev Méd Chile 2003;131:1405-10.

14. Centeno Robles MT, Pardo Romero M, Centeno Malfaz F, Ruiz Labarga C, Beltrán Pérez AI, Del Villar Galán R. Enanismo tanatofórico en embarazo gemelar. An Esp Pediatr 2000;52:191-4.

15. Machado LE, Bonilla-Musoles F, Raga F, Bonilla F, Machado F, Osborne N. Thanatophoric dysplasia: ultrasound diagnosis. Ultrasound Q 2001;17:235-43.

16. Byrne JLB. Thanatophoric Dysplasia. En: Woodward P, Kennedy A, Sohaey R. Diagnostic Imaging 
Obstetrics. Salt Lake City: Amirsys; 2005. p. 10-26 - 10-29.

17. Benacerraf BR. Ultrasound of Fetal Syndromes. 2nd. ed. Philadelphia: Churchill Livingstone; 2007.

18. Jeanty P, Silva S. Update by Leite J. Tanatophoric dysplasia 2006. Disponible en: http://www.TheFetus. net/page.php?id $=381$
19. Burmagina Y, kaloyanova E. Acondroplasia. Visitado en 2008 Oct 22. Disponible en: http://www. TheFetus.net/page.php?id $=2531$

20. Gómez R, Schepeler S. Displasias esqueléticas. En: Gratacós E, Gómez R, Nicolaides K, Romero R, Cabero L. Medicina Fetal. Madrid: Panamericana; 2007. p. 491-502.

Conflicto de intereses: ninguno declarado.

La forma en que se presenta la información protege la confidencialidad de la paciente. 